\title{
Chimpanzee Trisomy 22
}

National Cancer Institute

\section{Source}

National Cancer Institute. Chimpanzee Trisomy 22. NCI Thesaurus. Code C146897.

A condition resulting from the presence of an extra copy of chromosome 22 in

chimpanzees. The condition is in many respects similar to Trisomy 21 in humans. 